\title{
PRELIMINARY INDICATIONS TRIGGERING OPTIMIZATION OF INTERNAL PROCESSES
}

\author{
Radu-Eleonor SAMOILĂ \\ Bucharest University of Economic Studies, Romania \\ radusamoila2@gmail.com
}

\begin{abstract}
The success of today's businesses is heavily linked to the efficiency and effectiveness of their core processes. This importance is recognized by different researches and is triggered, mainly, by the rapid development of the global market and the increase of competitiveness. This article offers a high-level guide for company's management when deciding matters with regards to the optimization of internal processes. It focuses on the initial signals or indications that the companies need a business process assessment. More than this, the article discusses the main definitions offered by the specialized literature concerning the internal processes, process improvement and optimization evolution during time, as well as the data needed to be used in the decision making process for optimizations. The paper is designed to respond to certain questions with regards to when and what aspects should be assessed by companies for understanding if it's the right moment to do an optimization considering its strategy, availability and other matters. In addition, the articles proposes to highlight certain differences and similarities to what concerns process improvements and optimization and which semantics define best what organizations plan to undergone.
\end{abstract}

Keywords: process optimization, process improvement, optimization indications, business process.

JEL classification: C61, C69.

DOI: $10.24818 / \mathrm{ie} 2020.02 .09$

\section{Introduction}

Business processes were in the attention of many during last period of time. There was a great emphasis put on the business transformation programs aimed to increase the efficiency and effectiveness of company's internal processes. There were lots of approaches or techniques, many promises and expectations from the improvements concepts, however, the remarkable results were never obtained. This is the reason for which the companies become more and more reluctant to the whole concept of process improvement. In addition, the term of process improvement is widely used while the term of optimization has received less attention. In a nutshell, improvement refers mostly to the qualitative modifications brought to a process to improve its current state while, optimization, implies the introduction of the automation for improving an internal process. The optimization should be realized based on clear objectives which are assessed quantitatively.

\section{Internal processes: Definitions and Classification}

\subsection{Definitions}

There are many definitions for describing a business process. Most part of these definitions describe the internal process as a sequence of linked tasks or activities that, at every stage, consume one or more resources (employee energy, time, infrastructure, machines, and money) 
to convert inputs (data, material, and parts) into outputs (products, services, or information) [1]. The definition provided by Havey [2], is "a step-by-step rules specific to the resolution of a business problem". During time, there were significant number of definitions used, each author aiming to focus business processes on specific directions. The first most common used definition is the one provided by Hammer and Champy [3], who mention that "a business process is a collection of activities that takes one or more kinds of inputs and creates an output that is of value to the customer". The second one is given by Davenport [4], who sustains that "a business process is defined as the chain of activities whose final aim is the production of a specific output for a particular customer or market."

The main characteristics that define an internal process are the following:

- Resources: could be defined as the means each process should have in order to convert inputs into outputs. The resources are tangible, such as software or people, or intangible, such as skills or experience.

- Inputs: are the things which are converted by the process into an end-product or service that is, afterwards, utilized by the client. Those can be tangible, such as data, or intangible, such as approvals or requests.

- Activities: are all the actions that transform the inputs, through the process, into outputs. Those can be tangible, such as writing or measuring, or intangible, such as approving or requesting.

- Outputs: could be products or services which are sold to clients. Those can be tangible, such as products, or intangible, such as advices.

- Controls: are all activities or actions which are performed in order to ensure that the process is transparent, stable and working efficiently and effectively, according to the requirements.

\subsection{Classification}

Each organization comprises dozens of internal processes aimed to produce different types of outputs. The processes are designed by each organization depending on each one's way of doing business, considering benchmarks of their peers in the market or other practices. Depending on their nature, processes can be defined in three main categories:

- Business processes: are the processes that are creating the core-values for that specific organization. Also named the backbone or value chain of the organization, the business processes are expected to create the most value in the eyes of the client. The business processes may have front office or back-office activities such as sales orders processing, shipping or billing.

- Support processes: are the processes that sustain the organization core processes. These processes are usually standardized and could be subjects of process outsourcing. These processes could include finance and accounting, administrative, human resources or information technology.

- Management processes: exist to develop and provide the strategy or direction of the organization. Normally, these processes are managed by the senior leaders, which are setting the goals and objectives of the organization. These processes are usually concentrating on managing the resources, creating the strategy or developing the entire business.

These three categories of processes have to be aligned and integrated in order to maximize the value creating of business activities. When all tasks that define the business processes are well interlinked and follow a well-designed set of rules, there is less redundancies and duplicated effort, less errors and delays while the personnel and the clients of the organization feel more satisfied. 
www.conferenceie.ase.ro

\section{Process Improvement and Process Optimization}

The improvement of business processes have received ample attention in the attempt to enhance the efficiency and effectiveness in order to respond to market competitiveness and customers' needs. In these attempts, there were various terminologies used to define the improvements of internal processes. Part of those were process reengineering, process modelling, process analysis or process optimization. This article does not present details on these terminologies but, based on part of the studies literature, present the main advantages and disadvantages observed between them, as included in the Table 1 below.

\begin{tabular}{|c|c|c|}
\hline Approach & Advantages & Disadvantages \\
\hline Reengineering & $\begin{array}{l}\text { Presents structured and simple } \\
\text { steps to be followed. } \\
\text { High number of methodologies that } \\
\text { can be used. }\end{array}$ & $\begin{array}{l}\text { Mentioned as it sustain the process } \\
\text { improvement concept; however, } \\
\text { there few cases or examples where } \\
\text { it describes the specific steps to be } \\
\text { implemented to achieve } \\
\text { improvements. }\end{array}$ \\
\hline Modelling & $\begin{array}{l}\text { High number of techniques/models } \\
\text { available } \\
\text { The available techniques and } \\
\text { models are based on diagrams, } \\
\text { mathematics or programming } \\
\text { languages (e.g. xml). }\end{array}$ & $\begin{array}{l}\text { The techniques and the models are } \\
\text { quite complex and time } \\
\text { consuming. } \\
\text { The techniques and the models are } \\
\text { based, either on mathematical or } \\
\text { qualitative models, but not both. }\end{array}$ \\
\hline Analysis & $\begin{array}{l}\text { Includes visual analysis (e.g. } \\
\text { diagrams) or mathematical analysis } \\
\text { that allow quantification. } \\
\text { Involves accuracy in benefits } \\
\text { computation. }\end{array}$ & $\begin{array}{l}\text { It is based on subjective } \\
\text { interpretation of the analyst. } \\
\text { It is time consuming because it } \\
\text { requires observational analysis } \\
\text { that is based on the analyst's } \\
\text { experience. }\end{array}$ \\
\hline Optimization & $\begin{array}{l}\text { Offers several techniques which } \\
\text { can be used (e.g. graph reduction, } \\
\text { algorithmic approaches). } \\
\text { Allows automation, as the central } \\
\text { solution. }\end{array}$ & $\begin{array}{l}\text { There are no well-defined or } \\
\text { structured solutions, at the } \\
\text { moment, which can be followed by } \\
\text { the organization for obtaining } \\
\text { improvements. }\end{array}$ \\
\hline
\end{tabular}

As noticed, process modeling does not create too much value without further inspection and analysis of the business processes model. In addition, process analysis creates small value, unless it helps in improving or optimizing a business process [5]. The concept of process improvement can be implemented by using associated formal techniques [5] that support both the modeling and the analysis of internal processes. A holistic approach toward business processes should capture a business process (business process modeling), provide the necessary means for bottleneck identification and performance analysis, and, eventually, generate alternative improved business processes in terms of specified objectives.

There are several methodologies for restructuring internal processes, however, the analysts or designers are the ones who need to develop the optimal designs of business processes [6]. The optimization of business processes consists mostly on the automated improvement using predefined quantitative measures of performance (objectives). It could be, in many cases, the 
www.conferenceie.ase.ro

appropriate systematic approach to fill in the gap disclosed under the disadvantages presented in Table 1 above.

\section{Indications for internal processes' optimization}

Each organization initiate optimization programs starting from various reasons but all these programs have, usually, similar targets or aims. There are similar benefits expected even though the indications or the issues raised inside the organizations are different. The optimization efforts should enhance the core business of an organization by delivering better products and services, in a shorter period of time, at lower cost and with less environmental impact.

There are seven major categories [1] that include the indications for initiating an improvement or optimization program inside the organization.

\subsection{Organizational indications}

These indications are closely related to the difficulties encountered by organizations for coping with growth or planning for high growth. The growing strategy could include mergers and acquisitions which lead to additional complexity or lack of synergies. These cases could trigger optimization processes for aligning the internal processes and systems in order to eliminate certain redundancies, waste or doubling efforts.

Others indications to what concerns the organizational matters could be the following:

- Certain opportunities were identified in the market and need to be addressed through optimizations;

- The company's objectives are not being met;

- Decisions to change the corporate strategy to operational excellence;

- Certain changes in the legislative or compliance requirements.

\subsection{Personnel indications}

The employees of the organization could be a clear indications that the internal processes are malfunctioning which could lead to low employees' morale or satisfaction. These indications could be identified by observing the turnover of employees or other issues among them. Therefore, the main indications concerning the personnel which could trigger optimizations include:

- Large number of employees leaving the company (high employee turnover);

- The employees' morale or satisfaction is low. This is usually observed from internal surveys done among employees;

- Significant increase in the number of employees which can be a signal that certain processes are inefficient;

- Employees encounter difficulties in managing their processes due to continuous change and increasing complexity;

- Extensive manual intervention which is prone to human errors.

\subsection{Management indications}

In practice, most part of the optimizations are triggered by the management of the organization due to certain requirements to increase the processes transparency or the level of data availability. This is paramount in the decision-making process which involves senior or middle level management personnel. Other indications could be the following:

- Data or information is unreliable;

- Managers require additional control over the processes managed by them; 
- There is a need to create a culture of high performance within the organization;

- Initiatives that require budgets cuts;

- Requirements to obtain more capacity from existing personnel structure;

\subsection{Counterparty indications}

The creditors, suppliers or clients are the main counterparties which can trigger optimization. For example, creditors might impose specific covenants at certain levels in order to provide borrowings. Other indications could include:

- High increase in the number of suppliers or customers which create difficulties in managing the related processes;

- Long lead times to meet clients expectations;

- Clients or suppliers require standard processes;

- Low satisfaction with the service.

\subsection{Product and service indications}

These indications could include the following:

- The organization is not enough agile to respond to certain requirements addressed by the clients with respect to products developments or services;

- Long lead time to deliver the products or services;

- New products or services compromising existing products and service factors;

- Developing certain products require their own processes where most activities are similar or standardized;

- Poor stakeholders' engagement.

\subsection{Internal process indications}

These indications are one of the most important which require extensive analysis to identify the gaps or issues. These indications might include:

- Increase the transparency of the entire process (end-to-end perspective);

- The processes and not documented nor standardized;

- The roles and responsibilities of the personnel managing the processes are unclear;

- The quality of the products and services is low and does not meet the clients' requirements;

- The amount of rework is significant;

- Significant time passed since latest modifications brought to the internal processes or the processed are modified way too often;

- The are no objectives or goals set at organization or process levels;

- The communication is poor or inexistent among the employees managing the internal processes;

- There is significant number of gaps or issues in performing the internal processes.

\subsection{Technology indications}

The technology evolved extremely well during last decade allowing companies huge opportunities for optimizing (incl. automation) their internal processes. The main indications requiring technology driven optimization are:

- The desire to adopt new technologies or systems;

- The purchase of a business process management automation tools;

- Retirement of old applications and their replacement;

- The existent applications or systems are overlapping; 
www.conferenceie.ase.ro

- The current technology is not delivering as per expectations;

- The IT costs are considered to be high when compared to the value created inside the organization;

- The need to adopt the best technologies.

As previously mentioned, the optimizations have similar purpose for most part of the organizations. The main purpose is to eliminate or reduce waste. The waste is any resource consumed by nonessential activities, any unwanted material left over from a production process or any output that has no marketable value [1].

\section{Conclusions}

In conclusion, this article provides information with regards to the definitions used for internal processes inside an organization, it provides certain advantages and disadvantages of the main approaches addressing process improvements and highlights the need for automation while optimizing the internal processes. Currently, there is scarce support provided by most business process optimization techniques for structured process improvement. Even though then number of process optimization approached to be used is low, there are several attempts noted but those are overcomplicated and time consuming.

There were presented the main indications for initiating the optimization processes inside the organization. Each optimization has similar purposes or reasons no matter the industry of the organization. However, at the moment, due to the lack of approachable techniques available in the market, each organization, through their analysts or designers, should reanalyze and redesign their internal processes at the optimal levels desired. All these analyses should consider the indications and related nature in order to identify in time the future approach and necessary objectives of the optimizations.

\section{References}

[1] T. Boutros and J. Cardella, The Basics of process improvement, CRC Press.

[2] M. Havey, Essential Business Process Modelling. Sebastopol, CA: O'Reilly, 2005.

[3] M. Hammer and J. Champy, Reengineering the Corporation: A Manifesto for Business Revolution. London, U.K.: Brealey, 1993.

[4] T. H. Davenport, Process Innovation: Reengineering Work Through Information Technology. Boston, MA: Harvard Business School Press, 1993.

[5] W. M. P. van der Aalst, A. H. M. ter Hofstede, and M. Weske, "Business process management: A survey," in Lecture Notes Computer Sciences, Springer-Verlag, 2003, vol. 2678, pp. 1-12.

[6] I. Hofacker and R. Vetschera, "Algorithmical approaches to business process design," Comput. Oper. Res., vol. 28, 2001 